\title{
ReAlMente: AdvÉrbio ModAl E IMPlicAtUra GENERALIZADA
}

\author{
Roberta Pires de OLIVEIRA \\ MÁrcio RENATO GUIMARÃES
}

\begin{abstract}
The paper compares necessariamente $p, p$, and realmente $p$ in Brazilian Portuguese. It argues that realmente is an epistemic modal. The main difference with respect to necessariamente is the ordering source: the former takes the real world, the latter, the normal course of events. Realmente has a lexicalized ordering source: real-. The ordering is established by the similarity to the real world. The result is a hiper-realist basis. Thus, realmente $p$ entails $p$, but since it activates an ordering source, there are alternatives; it implies that there are non- $p$ worlds. To utter $p$ implies that the speaker is faithful. To utter realmente $p$ fires a generalized implicature that $p$ is in discussion, as claimed by Guimarães (2016), because it suspends the maxim of quality: it states that the real world belongs to $p$. We present the contours of this implicature.
\end{abstract}

Keywords: Brazilian Portuguese; modal adverbs; possible worlds semantics; pragmatics; implicatures.

Este artigo propõe uma aproximação da semântica e da pragmática de realmente no Português Brasileiro Contemporâneo ( $\mathrm{PB}$, de agora em diante). A perspectiva é linguística e nossa contribuição certamente não é em lógica, antes usamos o aparato formal como um instrumento que permite uma descrição menos ingênua das línguas naturais, em particular de como é essa capacidade que nos permite fazer sentido do que falamos. Nossa investigação é, portanto, de natureza empírica. Estamos interessados em explicar como é o conhecimento que um falante têm de sua língua natural. Os modais mostram que raciocinamos com premissas, como aparece claramente na proposta de Kratzer (2012). ${ }^{1,2}$ Nosso objetivo neste artigo é descrever a contribuição de realmente sem entrar em questões metafísicas, mas procurando compreender como é o aparato linguístico. Não há qualquer dúvida de que faz parte do nosso conhecimento semântico que há o mundo real, que é nele que estamos e por isso ele é privilegiado (para nós, obviamente!). Vamos assumir que esse é o caso e que trivialmente todos nós sabemos o que é o real, a realidade na qual vivemos. Essa é uma "margem dura", para usar uma metáfora de Wittgenstein (apud Martins \& El Jaick 2012).

Nossa hipótese é que realmente é um operador epistêmico maximal, porque ele seleciona o mundo real como mundo de avaliação e como fonte de ordenação; logo a base modal são os mundos que compartilham todas as informações com o real até Principia 20(1): 127-142 (2016).

Published by NEL — Epistemology and Logic Research Group, Federal University of Santa Catarina (UFSC), Brazil. 
aquele ponto no tempo e são ordenados segundo o mundo real. Trata-se, portanto, de um singleton, o próprio mundo real. Ele expressa que para o falante aquele é o mundo real. Essa semântica irá permitir derivar a sua função discursiva, descrita em Guimarães (2016), que afirma que ele dispara uma implicatura generalizada de que a proposição sobre a qual ele tem escopo — vamos denominar de sentença prejacente, seguindo a sugestão de von Fintel (2006) para os modais —, já está presente no discurso. Nossa proposta é que essa implicatura é gerada pela presença de uma fonte de ordenação não vazia, em contraposição a ausência de fonte de ordenação que, iremos argumentar, caracteriza o modo indicativo. Assim, parte do nosso trabalho é mostrar em que proferir realmente $p$ difere de proferir $p$.

Na primeira seção, apresentamos o estado da arte sobre realmente na linguística nacional. Discutimos a proposta de Castilho et al. (2014) de que ele é um modalizador epistêmico, esclarecemos esse conceito; defendemos que se trata de um modal epistêmico, cuja melhor paráfrase não é eu tenho certeza como sugerem esses autores, mas no real ${ }^{3}$ em contraponto a no sonho ou na ficção. Assim, não vamos nos deter no uso desse advérbio como o que foi denominado "intensificador", uma noção que merece um estudo a parte. Esse uso está exemplificado em (1):

(1) O João está realmente feliz com a nova casa.

Enquanto intensificador, ele teria a significação geral de muito, por que poderia ser substituído. Dado que a leitura de intensificação depende da existência de um adjetivo (ou de outra expressão) graduável, como é o caso de feliz, esse uso não é possível em construções que não envolvam essa gradação. Além disso, exige que o advérbio esteja adjungido ao predicado gradual que ele modifica. Compare com (2):

(2) Realmente o João está feliz com a nova casa. ${ }^{4}$

A interpretação mais natural é que o falante está se comprometendo fortemente com a proposição, o que ele só faria se a proposição estivesse de alguma forma em suspensão, sob suspeita ou pudesse estar sob suspeita. O falante mantém que tem evidências de que João está feliz a despeito de que essa afirmação possa ser posta em questionamento. Essa interpretação, iremos argumentar, é uma implicatura conversacional generalizada associada a semântica de realmente. Para isso, investigamos a diferença entre (2) e (3):

(3) O João está feliz com a casa nova.

Uma primeira solução, na esteira de Grice (1975), é supor que realmente dispara uma implicatura convencional, como ocorre com mas. Isto é, não interfere nas condições de verdade, não contribui com o dito. Na segunda seção, investigamos essa hipótese com base nos testes propostos por Bach (1999). Mostramos que realmente é proposicional. Bach argumenta que as implicaturas convencionais não existem; que os 
ACIDs (Alleged Conventional Implicature Devices) veiculam uma proposição secundária, processada em paralelo à proposição principal (Semântica Multidimensional). Esse não é o caso de realmente. Não se trata portanto de uma implicatura convencional ou um ACID, também não é o caso que ele é um afetivo como infelizmente. Nossa proposta é que se trata de um operador proposicional como necessariamente, um quantificador sobre mundos possíveis.

Ela parte de uma análise morfológica trivial que enxerga a contribuição lexical dada por real em real-mente. Nesse sentido ele se opõe ao que é ficcional, ao adjunto adverbial no meu sonho, por exemplo. Sem entrar nos detalhes sobre a semântica do modo indicativo, assumimos que é quantificação universal restrita aos mundos compatíveis com o mundo de avaliação (que, sem nenhuma outra informação, é o mundo real), mas não há nenhuma fonte de ordenação. Logo, todos estão igualmente acessíveis, enquanto que em (2) a fonte de ordenação é o mundo real. Com isso o falante singulariza o mundo real e afirma que p é o caso tendo em vista esse pano informacional. Apresentamos a semântica na terceira seção. A presença de uma fonte de ordenação coloca alternativas e, portanto, outros mundos em que p não é o caso; ter alternativas a p gera uma implicatura. Finalmente, nos debruçamos sobre a questão colocada em Guimarães (2016): como explicar que proferir (2) veicula normalmente que o falante está concordando com algo que já foi dito antes. Essa interpretação, de longe a mais estudada, tem sido apontada, na pouca literatura sobre o tema, como um caso de "polifonia": realmente "evoca polifonicamente opiniões divergentes", aparece em Ilari (1996, p.207). Não é preciso haver opiniões divergentes. O fato de que o falante escolheu explicitar que p é o caso tendo em vista uma ordenação em que o mundo real é o ideal implica que $p$ está sob dúvida, afinal o falante está sendo redundante, já que apenas afirmar $p$ já é se comprometer que $p$ é o caso. Proferir (2) implica que a sentença prejacente, que está no escopo nuclear, já faz parte do discurso, quer porque ela está em suspenção quer porque ela é muito inusitada e é preciso enfatizar que esse é o caso. Nosso objetivo, na última seção, é esboçar os contornos dessa implicatura.

Nem é preciso dizer que estamos em águas mais do que turbulentas. Muitas questões nem mesmo se colocaram e este artigo é antes um convite para mais investigações.

\section{Modalizadores Epistêmicos}

A literatura nacional sobre o realmente no $\mathrm{PB}$, que conhecemos, não discute se a contribuição interpretativa desse advérbio é semântica ou pragmática, talvez porque essa distinção faça pouco sentido no funcionalismo que embasa essas propostas. Mas mesmo nessa tradição é preciso explicar o mais claramente possível o que dizemos quando proferimos uma sentença em que esse advérbio ocorre. A tese central 
é que ele veicula certeza. Castilho (2000), Paradis (2004), Lacerda (2012) e mais recentemente Castilho et al. (2014) caracterizam realmente como um modalizador epistêmico, que expressa certeza, diferenciando de advérbios como provavelmente e possivelmente, modalizadores epistêmicos que exprimem possibilidade. Castilho et al. (2014) afirma que realmente está na mesma lista de naturalmente, obviamente, logicamente, inegavelmente... E assim definem a sua contribuição: "os modalizadores de certeza podem ser representados pelo predicador abstrato "eu sei com certeza que $P$ ”, em que $P$ corresponde ao conteúdo sentencial" (2014, p.287). Essa definição permite incluir na lista necessariamente, embora os autores não tenham feito isso. Vamos nos deter nessa proposta.

Os exemplos dos autores, todos retirados do NURC, ${ }^{5}$ exigem, cada um a seu turno, uma análise detalhada. No comentário ao exemplo 7 , na página 288 , reproduzido abaixo em (4), os autores propõem uma derivação sintático-semântica que está correta, mas que precisa ser explicada: afinal por que realmente tem necessariamente escopo mais amplo?

(4) Ter uma família grande deve ser uma delícia, realmente.

Há muitas dificuldades para atribuirmos uma semântica para essa sentença e certamente o que os autores propõe é um início de conversa. Se acompanhamos a sua descrição para (4), chegamos a algo como:

(5) Realmente [deve [ ser uma delícia (ter uma família grande)]]

Não há etiquetas, logo não sabemos sobre os tipos semânticos ou nós sintáticos com os quais estamos lidando. Além disso, esse exemplo é bastante complexo, como os próprios autores afirmam, porque realmente tem escopo sobre uma sentença modal encabeçada por deve, cuja semântica é complexa, como sabemos, e a sentença mais encaixada, em (5), é um genérico, que tem uma sentença infinitiva na posição interna do predicado é uma delícia. ${ }^{6}$

Não é simples refazer passo a passo toda essa derivação. Para os nossos propósitos só interessa que intuitivamente realmente ganhou escopo mais amplo e nem é mesmo questionada a possibilidade do auxiliar modal ter escopo sobre o advérbio: Deve ser o caso que realmente é uma delícia ter uma família grande. A leitura "é provável que seja o caso na realidade que é uma delícia ter família grande", simplesmente não está disponível. Note que mesmo forçando, a única interpretação é realmente com escopo mais amplo Se esse for o caso, estamos dando suporte para uma predição da hierarquia de projeções de Cinque (1999), segundo a qual se realmente é um epistêmico, então ele deve ocupar a posição mais alta. Há, mais uma vez, um tanto de coisas para entendermos sobre isso, mas esse é um dado que irá nos guiar. Aparentemente, realmente não pode ficar sobre o escopo de outros operadores, nem mesmo da negação:

Principia 20(1): 127-142 (2016). 
(6) João realmente não saiu.

A interpretação de que a saída do João ocorreu, mas não no real - Não é real que o João saiu - simplesmente parece interditada. A única possibilidade é que na realidade o João não saiu. Os autores não discutem essa propriedade. Afirmam que a paráfrase para esse advérbio é eu tenho certeza. Por um lado, isso é andar em círculo, porque agora precisamos entender o que ter certeza significa. Em que (7) é mais claro que (4)?

(7) Eu sei com certeza que ter uma família grande deve ser uma delícia.

Além disso, um indício de que realmente não tem o mesmo significado de eu tenho certeza aparece no exemplo dado pelos autores imediatamente antes do exemplo em (4):

(8) então eu acho realmente.

Segundo a análise proposta, (8) veicularia o mesmo significado de (9):

(9) então eu acho (que) eu tenho certeza.

Mas, (9) não é a paráfrase de (8). Do ponto de vista da semântica, a questão a ser colocada é: qual é a contribuição de realmente? Ele dá alguma contribuição semântica? Para isso, a melhor metodologia não é tomar uma sentença em (4) como um ponto de partida para a análise porque, além da sua complexidade, ela parece veicular que o falante está concordando com algo que já foi dito antes, a implicatura que iremos discutir na quarta seção. Se queremos fazer uma análise semântica, o melhor é diminuir ao máximo os atritos e buscar exemplos em que há o mínimo de interferência. Esses são os exemplos de laboratório que os linguistas constroem. Há, no entanto, dados que são pontos de partida mais claros como em:

(10) diversos outros locais que é difícil acreditar que realmente pertencem a esse planeta. $^{7}$

Há vários outros locais que, embora pareçam ficcionais, de fato são reais. Note que realmente a despeito de aparecer superficialmente sob o escopo de acreditar, na verdade é interpretado como estando fora de seu escopo. Mais uma vez, realmente tem escopo mais amplo. Note ainda a inadequação de substituir por eu tenho certeza: diversos outros locais que é difícil acreditar que eu tenho certeza de que pertencem a esse planeta. Para entendermos a contribuição desse advérbio é preciso investigar se ela é proposicional. 


\section{Implicatura convencional?}

Podemos imaginar que realmente não dá nenhuma contribuição semântica, isto é não afeta as condições de verdade da sentença a qual ele se adjunge. Desse ponto de vista, (11a) e (11b) são verdadeiras exatamente nas mesmas situações (e só nelas):

(11) a. O João chegou antes das 10 ontem à noite.

b. O João realmente chegou antes das 10 ontem à noite.

Elas são verdadeiras se e somente se o João chegou antes das 10 na noite anterior ao proferimento. Se é isso, podemos estar diante de uma implicatura convencional que é, segundo Grice, não cancelável porque é parte do item lexical. Considere o exemplo abaixo:

(12) A Maria ainda não chegou.

Grice (1975), na tradição que remonta a Frege, entende que ainda não afeta as condições de verdade já que (12) é verdadeira se Maria não chegou. Bach (1999) argumenta que se for esse o caso, em contextos reportados, a contribuição de ainda está fora da proposição veiculada. O teste se ampara na análise feita por Frege para o discurso reportado . No discurso reportado, o que importa é o sentido (e não a referência). Assim é possível substituir as expressões desde que seja mantido o sentido. Bach argumenta que se ainda não interfere nas condições de verdade, se ele não é proposicional, então, ao ser reportado, não faz parte do que está sendo reportado e irá portanto remeter ao falante e não ao sujeito gramatical. O que faz parte do que foi dito deve aparecer na fala reportada, como parte do conteúdo veiculado pela fala do sujeito gramatical. Caso contrário, o conteúdo será atribuído ao falante, como parece ser o caso de expressões como essa droga de:

(13) A Maria disse para desligar essa droga de TV.

Quem está avaliando que a situação é uma droga não é a Maria, o sujeito gramatical, cuja fala está sendo reportada, mas o falante, quem reporta a fala de Maria. É o falante que, por alguma razão, não está feliz com a situação. Assim, o que não afeta as condições de verdade remete sempre ao falante e não ao sujeito gramatical do verbo dicenti. Bach argumenta que ao aplicar esse teste ao que ele chama de ACIDS (Alleged Conventional Implicature Devices), essas expressões se comportam como parte do conteúdo que foi expresso pelo sujeito gramatical no discurso reportado. Assim, para ele quem afirma que a Maria deveria ter chegado mas não chegou, na sentença em (14) abaixo é o Paulo, o sujeito gramatical, e não o falante:

(14) O Paulo disse que a Maria ainda não chegou.

Principia 20(1): 127-142 (2016). 
Contraste com o exemplo acima em (13). Logo, o que ainda veicula é proposicional, ao passo que essa droga de é um afetivo, veicula a posição subjetiva do falante.

Se realmente contribui para o conteúdo proposicional, esperamos que, no discurso reportado, ele remeta ao sujeito gramatical e não sobre o falante.

(15) O Paulo disse que realmente o João chegou antes das 10 ontem à noite.

Esse é um teste bastante delicado porque depende da curva entoacional que acompanha o proferimento; em um proferimento com curva prosódica de afirmação neutra, portanto, sem foco prosódico no advérbio, temos, na nossa intuição, que é o Paulo que se comprometeu com a informação de que o João chegou antes das 10 e não o falante. ${ }^{8}$ Se é assim, então ele afeta o conteúdo proposicional. Suponha que sim.

Há, no entanto, uma outra propriedade dos ACIDs que Grice já havia descrito e que Bach utiliza para propor uma nova maneira de fazer semântica: as implicaturas convencionais podem ser falsas enquanto que a proposição principal é verdadeira. Grice discute o famoso exemplo He is brave therefore he is English (Ele é valente, pois é inglês). Esse proferimento carrega uma interpretação de relação causal entre ser valente e ser inglês: ele é valente porque é inglês. É possível entender que não há relação causal e manter que ele é valente e inglês. Bach mostra que não há implicaturas convencionais porque no teste do discurso reportado elas rementem sempre ao sujeito gramatical, indicando que o conteúdo que elas veiculam é parte do conteúdo proposicional, mas concorda que é possível que a informação, implicada para Grice, seja falsa, ao passo que a informação principal seja verdadeira. A solução para esse autor é que os ACIDs veiculam duas proposições em paralelo. Se elas se combinarem via conjunção (Ele é valente e inglês e ser inglês causa ser valente), então não seria possível que elas tivessem valores de verdade distintos. No entanto, esse parece ser o caso.

Se realmente for uma implicatura convencional/ACID esperamos o mesmo comportamento. Assim, ele deveria veicular dois sentidos de modo independente. Intuitivamente, realmente significa de acordo com o real. A pergunta agora é: é possível que seja verdade que João realmente chegou antes da 10 ontem à noite e seja falso que ele chegou antes das 10 ontem à noite? Nossa intuição é que esse não é o caso. Logo, não há dois conteúdos sendo veiculados. Em conclusão: realmente afeta o conteúdo proposicional diretamente, isto é, ele é um operador proposicional, logo faz parte do dictum. A consequência é que (11a) e (11b) não têm o mesmo significado, não expressam a mesma proposição. É esse o tópico da próxima seção.

\section{Uma proposta semântica para realmente}

Não é tarefa fácil explicar a diferença semântica entre as sentenças em (11), repetidas abaixo por conveniência.

Principia 20(1): 127-142 (2016). 
a. O João chegou antes das 10 ontem à noite.

b. O João realmente chegou antes das 10 ontem à noite.

Embora seja possível argumentar que o modo indicativo é o modo do realis, ${ }^{9}-$ ainda mais quando estamos diante do pretérito perfeito como em chegou que parece expressar que o evento descrito ocorreu no mundo real - , esse certamente não é o caso. Sonhos são relatados usando o pretérito perfeito: ${ }^{10}$

(17) No sonho, o João chegou antes das 10 ontem à noite.

(17) não é contraditória, mas deveria ser se chegou expressasse realis. Também é claro que em situações normais, o uso do indicativo associado ao pretérito perfeito indica que estamos falando sobre o mundo real. A máxima da qualidade irá garantir essa interpretação.

Não há consenso sobre como tratar o modo indicativo, mas uma vertente bastante influente explora a ideia de que esse modo indica que há quantificação universal, ao passo que o subjuntivo indicaria uma quantificação existencial (cf. Giannakidou 1995, 2009). Assim, (17) diria que em todos os mundos que são compatíveis com o conteúdo do sonho, é o caso que João chegou antes das 10. Se adotamos Kratzer (2012) como suporte teórico, os adjuntos adverbiais no sonho e na minha opinião indicam explicitamente a base modal, porque estabelecem qual é o mundo de avaliação e portanto qual é o corpo de "conhecimento" que está sendo acionado e o indicativo quantifica universalmente sobre esses mundos.

A sentença em (16a) expressa semanticamente que em todos os mundos que são compatíveis com algum mundo de avaliação é o caso que João chegou antes das 10 , sem, no entanto, identificar explicitamente a base modal que é então deixada para ser preenchida pelo contexto. Se nenhuma outra informação é dada, ceteris paribus, assumimos que se trata do mundo real, via enriquecimento pragmático ou uma variável de contexto atada ao tempo do proferimento. Se é assim, então o modo indicativo é um operador modal realizado através da flexão verbal, no caso do PB. Assim tanto (16a) quanto (16b) são sentenças modais em sentido estrito: há quantificação sobre mundos possíveis. Antes de detalhar a diferença entre elas, vamos revisar a semântica dos operadores modais epistêmicos.

Operadores modais são quantificadores sobre mundos possíveis: relacionam uma base modal ordenada e uma proposição. A literatura sobre modais epistêmicos é vasta. De modo ingênuo, eles manipulam informações com o intuitio de expressar uma possível informação nova. "Epistemic modals are interesting in part because their semantics is bound up both with our information about the world and with how that information changes as we share what we know." (Von Fintel \& Gilles 2007, p.32). Estamos diante de modais epistêmicos quando acionamos um corpo de conhecimentos que serve de premissas para um raciocínio. $\mathrm{O}$ advérbio necessariamente na 
sentença em (18) é um modal epistêmico. A partir de um corpo de conhecimento dado contextualmente, chega-se a única conclusão possível: o João chegou antes das 10. Suponha, por exemplo, que sabemos que a porta do dormitório fecha às 10 e que não há outra maneira de João chegar ao seu quarto. Sabemos ainda que ele está dormindo em seu quarto no momento em que houve o proferimento, mas não sabemos que horas ele chegou e estamos raciocinando a partir desse corpo de evidências:

O João necessariamente chegou antes das dez, ontem.

Seguindo Kratzer (2012), operadores modais são quantificadores que estabelecem uma relação entre a base modal, que é ordenada pela maior ou menor proximidade com os mundos ideais, e a proposição. A base modal ordenada pode ser fornecida pelo contexto ou dada lexicalmente, como é o caso de realmente. A base modal epistêmica caracteriza-se por ser realista, isto é ela se estrutura a partir do que se sabe sobre o mundo de avaliação e é reflexiva, ela inclui esse mundo. Mas ela pode ser ordenada por diferentes tipos de fonte. No caso da interpretação que sugerimos para (18) adotamos um corpo de conhecimento do falante que foi ordenado segundo o que é normal, uma normalidade, supomos que as coisas se comportaram normalmente - é essa fonte que utilizamos quando interpretamos o progressivo, por exemplo. Significa que estamos excluindo inúmeros mundos e ordenando os mundos que constituem a base tendo como ideais aqueles em que os eventos ocorrem inercialmente, sem acidentes, sem aberrações, por assim dizer. No nosso raciocínio, excluímos mundos em que o João é teletransportado, por exemplo, porque esse não é um mundo normal.

Note que sem essa ordenação, inferimos de (18) que o João efetivamente chegou às 10 , o que não condiz com a nossa intuição, a menos que o interlocutor seja um filósofo que dirá que necessariamente é o caso em todos os mundos, afinal 'necessariamente $2+2=4$ ' é necessariamente verdadeira. Há várias maneiras de resolver esse impasse, por exemplo, assumindo que há mais de um necessariamente, como faz a lógica clássica. A solução via ambiguidade tem consequências empíricas na linguística, entre elas, esperamos que em pelo menos uma língua haja dois itens diferentes, um para cada significado de necessariamente. Dado o que sabemos, a melhor alternativa é uma proposta unívoca como é o caso em Kratzer. Nessa proposta, a diferença entre os sabores da modalidade é dada manipulando dois parâmetros contextuais, a base modal e a fonte de ordenação. No caso do lógico, que é um caso extremo, a base modal contém todos os mundos possíveis; é o estado mínimo de conhecimento - não sabemos nada porque todas as alternativas são válidas - e a fonte de ordenação é vazia - todas as alternativas têm o mesmo peso. Os mundos da base modal são então igualmente válidos, não há gradação. Daí que $2+2=4$ é sempre válido, sem qualquer restrição. Esse é o caso do necessariamente alético. Nesse caso, necessariamente acarreta $p$.

Esse não seja é o caso em (18). Não estamos no domínio máximo, porque estamos 
falando sobre o que ocorreu no dia anterior; restringimos a base modal apenas aos mundos que são compatíveis com aquela gama de conhecimento. Além disso, não é claro que (18) acarreta (16a). Esse é um ponto controverso. Kratzer entende que não há acarretamento. Estamos falando de uma necessidade humana, diz a autora. Tendo em vista o que sabemos — há um conhecimento parcial —, a melhor aposta é que houve o tal do evento da chegada de João, mas esse é o resultado de um raciocínio, de uma inferência e portanto sempre sujeita ao erro. Assim, (18) não acarretaria (16a). (18) acarreta que houve o evento de chegada antes das $10 \mathrm{em}$ todos os mundos ideais, isto é aqueles em que as coisas se comportam conforme o esperado no raciocínio. Mas talvez as coisas não se comportem assim no mundo real, porque pode estar falando uma informação nesse raciocínio. Por exemplo, ninguém sabe que João tem uma chave da cozinha. A Semântica de Ordenação de Kratzer permite esse ajuste.

Nessa semântica, a base modal é uma função que atribui a cada mundo o conjunto de mundos que compartilham com o mundo de avaliação os fatos (são os mundos que estão na interseção dessas proposições). Além disso, essa base modal é relativizada a um conjunto de proposições que delimitam os mundos ideais. Na interpretação humana de necessariamente os mundos estão restritos por aquilo que sabemos sobre o mundo de avaliação e a fonte de ordenação é a normalidade: em todos os mundos compatíveis com o mundo de avaliação (que é normalmente o mundo real) que estão mais próximos daqueles em que os eventos transcorrem normalmente, João chegou antes das 10. Na necessidade alética, não há restrição aos mundos e a fonte de ordenação é vazia porque o conhecimento é zero. Kratzer propõe ainda a situação maximamente realista em que na base modal só há um único mundo, que identifica um mundo em particular. Na interpretação humana, estamos no meio do caminho entre esses extremos, sabemos um tanto, mas não sabemos tudo, nem mesmo sobre o nosso mundo. Assim, em todos os mundos que estão próximos dos mundos ideais (aqueles em que não há acidentes ou fatos inesperados), é o caso que João chegou antes das 10, mas não há qualquer garantia de que o mundo real esteja entre os ideais. Afinal, sempre pode ser o caso que o João arrumou uma chave que permite ele entrar no dormitório sem que ninguém saiba e ele na verdade chegou bem depois da uma da manhã. Assim necessariamente $p$ humano é mais fraco que $p$; não acarreta $p$. Mas necessariamente $p$ alético acarreta $p$.

Se realmente é um modal epistêmico, ele aciona um conhecimento, isto é, ele relaciona uma base realista (reflexiva) ordenada segundo alguma fonte. Nossa proposta é não apenas os mundos que constituem a base modal compartilham os fatos com o mundo real, mas o mundo real é o parâmetro para os mundos ideais: dado os mundos que compartilham os fatos com o mundo real e organizando os mundos segundo esse mundo real, $p$ é o caso. realmente gramatiza a situação maximamente realista, que identifica um mundo em particular, o mundo de avaliação. A diferença 
entre (16b) e (18) é que em (18) a fonte de ordenação é a normalidade, ao passo que em (16b) são os mundos maximamente semelhantes ao que o falante sabe sobre o mundo de avaliação. Logo, realmente $p$ acarreta $p$, já que $p$ é verdadeiro em todos os mundos ideias e o mundo real está entre os ideais. Veja que esse não é o caso com necessariamente. Nesse sentido, realmente é mais forte do que o necessariamente humanoA restrição de necessariamente humano é duplamente sensível ao contexto, enquanto que a restrição de realmente está fixada pelo item lexical: são os mundos que são maximamente compatíveis com o mundo real organizados tendo o mundo real como ideal. Suponha que essa é a função semântica de realmente: ele restringe a base modal aos mundos que são compatíveis com o mundo real e a fonte de ordenação é dada pelo mundo real, logo em todos os mundos que são maximamente semelhantes ao real (e o real é maximamente semelhante a si mesmo), $p$ é o caso. (16b) é parafraseada como:

(19) Em todos os mundos que são compatíveis com os fatos no mundo real e organizados segundo o mundo real é o caso que João chegou antes das 10 ontem.

Vale a pena retornar ao nosso par em (16) para esclarecer a diferença. Na sentença sem o advérbio, há quantificação universal restrita aos mundos semelhantes ao de avaliação e a fonte de ordenação é vazia, ou seja, não há gradação entre os mundos; todos eles pertencem a $p$. Em (16b), há uma fonte de ordenação, que é o mundo real, e isso faz toda a diferença': por um lado, introduz alternativas, já que há ordenação e, por outro, afirma que para todos os mundos que são maximamente semelhantes ao real, isto é o próprio real, $p$ é o caso. Em outros termos, apenas com realmente se entretém a hipótese de que há mundos que embora muito semelhantes ao real não pertencem a $p$.

\section{Derivando a implicatura generalizada}

Como já dissemos, a literatura sobre realmente deu muita atenção ao seu uso chamado de uso discursivo ou polifônico, nas palavras de Ilari. Embora as teorias tenham propostas distintas, como mostra Guimarães (2016), elas compartilham a ideia de que há uma outra fala, por isso estaríamos diante de um proferimento polifônico (várias vozes) que ou confirma o que já foi dito ou se opõe a esse dito. Descritivamente, o conteúdo veiculado por essa fala, que é retomada, está de alguma forma em dúvida e realmente confirma ou não essa fala. Descritivamente, um falante proferiu $p$, mas há dúvidas sobre $p$, então afirma-se que realmente $p$, confirmando que $p$ é o caso. O exemplo (25) representa um caso em que a confirmação é feita dialogicamente, numa negociação de comprometimentos entre os falantes:

Principia 20(1): 127-142 (2016). 
(20) Começa a circular em Florianópolis hoje, fazendo a linha 233 (Trindade/Canasvieiras) da empresa Canasvieiras, um ônibus com acesso para bicicletas. Infelizmente, o veículo está por aqui apenas para ser testado. O ônibus utiliza a tecnologia Euro V, com padronização de pintura para a Copa do Mundo.

\section{COMENTÁRIOS:}

C1: Que reportagem estranha ... não diz como funciona, não fala onde ele estará na copa ... Que falta de informação!!

C2: Ta... e????? Pra q é? Poder carregar bicicletas? Expliquem melhor!

C3: Realmente muito pobre de informações a reportagem ...

C4: Estamos tão atrasados em relação a mobilidade urbana que muitos nem imaginam o que já existe ao redor do planeta. [...] Realmente, a matéria poderia ser mais elucidativa. Um começo bem simplista, mas um começo.

C5: REALMENTE A RECLAMAÇÃO PROCEDE, FALTAM INFORMAÇÕES SOBRE O ASSUNTO!!!

[http://wp.clicrbs.com.br/visor/2013/10/08/passagem-para-bicicleta/?topo=67,2,18,,67]

Guimarães entende que a contribuição pragmática de realmente $p$ é indicar que $p$ já faz parte do fluxo do discurso e está sendo retomada para ser confirmada. Esse certamente é o caso no diálogo acima. Um dos falantes, C1, afirma que o artigo em questão é pouco informativo. A fala de C1 é confirmada, por mecanismos distintos, pelos vários falantes $\mathrm{C} 2, \mathrm{C} 3, \mathrm{C} 4$ e C5 que supostamente leram a notícia e concordam que ela é pouco informativo. C3, C4 e C5 usam realmente para realizar essa operação.

Para Guimarães, essa contribuição, poderia, num primeiro momento, nos deixar em dúvida entre caracterizá-la como uma implicatura convencional ou uma implicatura generalizada. O autor argumenta que não é possível ser uma implicatura convencional porque ela não está "convencionalmente" associada a esse item lexical, no sentido de que ela não é constante nos usos de realmente, ou seja pode ser cancelada. Os exemplos abaixo mostram que realmente pode não retomar algo já dito:

(21) LOC. - Quando eu saí do Rio para Belo Horizonte eu senti muito mais a diferença...

DOC. - Hum. Isso que eu ia lhe pedir pra senhora contar.

LOC. - Do que ... Muito mais. Quando eu cheguei em Curitiba, realmente no primeiro momento eu achei Curitiba mais atrasada do que eu esperava. Mas como eu fui no ano cinquenta e dois, que foi o ano de Curitiba ... Começou a crescer, que houve os festejos de centenário e que houve muita construção nova [... A Agora, em Belo Horizonte eu senti mais a diferença. Primeiro que quando eu fui também fiquei uns tempos em pensão enquanto procurava casa.

[PROJETO VARSUL — RIO DE JANEIRO]

Principia 20(1): 127-142 (2016). 
(22) LOC. - Não que fosse diferente não. As panelas, tudo comum. Hoje em dia o que pode haver era o que antigamente nós chamávamos de alguidar que era de...

DOC. - Ah, alguidar?

LOC. - Era de, era de barro, meio vidrado, que fazia as vezes de hoje dessas vasilhas que se compram pra, pra batedeira, né, pra fazer bolo. Então eram usadas e nós chamávamos de alguidar. Isso realmente hoje não se usa mais. Mas no mais eu acho que era tudo igual.

[PROJETO VARSUL — RIO DE JANEIRO]

(23) DOC. Hoje em dia existe uma série de aparelhos elétricos [...] Como era (inint.) naquela época se resolvia?

LOC. Não, realmente o bolo era tudo batido à mão, com garfo. Isso não tem dúvida.

[PROJETO VARSUL — RIO DE JANEIRO]

A ideia de que algo é retomado não ocorre em todos os contextos como aparece claramente no exemplo em (10) - diversos outros locais que é difícil acreditar que realmente pertencem a esse planeta. Guimarães sugere que se trata, então, de uma implicatura generalizada. Apresentamos, a seguir, os contornos do funcionamento dessa implicatura generalizada tendo como ponto de partida a semântica associada a esse advérbio desenvolvida na seção anterior.

O primeiro passo é propor uma descrição mais formalizada do diálogo entre C1 e C3 exemplificado acima. No modelo discursivo que teve início com Stalnaker (1968), o fundo conversacional compartilhado é o conjunto de proposições que são consideradas verdadeiras pelos interlocutores em um dado instante da conversação. Por exemplo, faz parte do nosso fundo compartilhado que a Terra é um dos planetas que orbitam ao redor do Sol, que no momento em que escrevemos este artigo, outubro de 2015, Dilma Rousseff é a presidente do Brasil e muitas outras pressuposições. Mas não faz parte do fundo compartilhado que está chovendo hoje. Ao analisar os modais, Portner (2009) propõe um "cinturão", uma região em que estão as possibilidades, as probabilidades, os condicionais e outras expressões que de alguma forma não podem fazer parte do fundo conversacional porque sua contribuição não permite excluir estados do mundo. Sentenças modais como pode $p$ são verdadeiras, mas não podem atualizar o fundo com $p$. O diálogo acima mostra que proferir $p$ não pode ser equiparado a introduzir $p$ no fundo conversacional, mas a sugerir que tal inclusão ocorra. Se uma proposição entra no fundo conversacional, ela atualiza aquele fundo ou contexto de tal forma que aquilo que é incompatível com $p$ é chutado para fora. Proposições que atualizam o fundo, eliminam estados de coisas que são incompatíveis. Por exemplo, se a proposição $O$ artigo é pouco informativo for aceita pelos 
interlocutores e atualizar o fundo, então no novo fundo só há mundos em que o artigo é pouco informativo; eliminam-se aqueles em que o artigo é mais informativo.

O que ocorre no diálogo em (25) é uma negociação sobre como atualizar esse fundo. O falante $\mathrm{C} 1$ propõe que o fundo conversacional seja atualizado com a proposição de que falta informação no artigo sobre os ônibus que carregam bicicletas. Se aceita, então são eliminados todos os mundos em que não há falta de informação no artigo. Em geral, afirmações são automaticamente incorporadas ao fundo conversacional, atualizando-o. Mas esse mecanismo pragmático pode ser suspenso por várias razões. No diálogo acima, ele parece não estar operando porque se trata de um artigo de um jornal, d que são veículos de informação por excelência. Assim, é plausível que a afirmação de C1 seja posta em dúvida. O falante C2 fornece mais argumentos para a afirmação de $\mathrm{C} 1$ de que o artigo é pouco informativo, o que mostra que a afirmação de que o artigo é pouco informativo está em discussão; no cinturão, portanto. C3 ao proferir realmente $p$ indica que levou em consideração outras situações e que dado o que ele sabe sobre o mundo real e ordenando esses mundos segundo esse mundo, $p$ é o caso.

Se a única diferença entre a afirmativa sem o advérbio e a sentença com realmente é a presença de uma fonte de ordenação, então o falante sinaliza com realmente $p$ que está entretendo outras hipóteses, que há mundos compatíveis com o mundo real mas que não pertencem a $p$. Por que o falante está afirmando que entretém outras hipóteses, em particular que $p$ não seja o caso, ao mesmo tempo que afirma que $p$ é o caso no mundo real? Um dos motivos é que $p$ está em discussão. A afirmativa sem o operador modal não coloca outras alternativas. Assim, realmente $p$ implica que $p$ já está no discurso, mas não faz ainda parte do fundo conversacional compartilhado.

\section{Conclusão}

Neste artigo apresentamos uma primeira proposta para a semântica de realmente. Defendemos que ele afeta as condições de verdade e é um advérbio modal como necessariamente, mas que tem um comportamento distinto porque carrega a informação da raiz real. Comparado a outros modais epistêmicos como necessariamente humano, notamos que é possível que ele seja encarado como se situando em uma espécie de ordenação com relação aos outros epistêmicos. Enquanto possivelmente e necessariamente (ao menos em seus usos estritamente epistêmicos) representam o nível em que as proposições ainda estão sendo avaliadas para a determinação de seus valores de verdade, realmente pode representar o ponto de culminação desse processo. Essa diferença está na fonte de ordenação, enquanto operadores como necessariamente tem a fonte de ordenação dada pelo contexto e não há garantia de que o mundo real esteja entre os ideais, a fonte de ordenação com realmente é fixada lexicalmente,

Principia 20(1): 127-142 (2016). 
estamos falando dos mundos que são maximamente próximos ao real e ordenados por esse mundo. O aprofundamento dessa e de outras questões fica para trabalhos futuros.

\section{Referências}

Bach, K. 1999. The myth of conventional implicature. Linguistics and Philosophy. 22(2): 32766.

Borges neto, J.; Müller, A.; Pires de Oliveira, R. 2015. A semântica formal das línguas naturais: histórias e desafios. Disponível em http://linguistica.fflch.usp.br/sites/linguistica.fflch.usp. br/files/u87/BORGES\%20NETO,\%20MULLER,\%20\%20PIRES\%20DE\%20OLIVEIRA_SE MANTICA\%20FORMAL.pdf. Acesso em 30 de outubro de 2015.

Castilho, A. T. 2000. O modalizador realmente no português falado. Alfa (São Paulo) 44(1): 147-69.

Cinque, G. Adverbs and functional heads: a cross-linguistics perspective. New York, Oxford: Oxford University Press.

von Fintel, K. 2006. Modality and Language. In Encyclopedia of Philosophy, second edition, edited by Donald M. Borchert. Detroit: MacMillan Reference USA. Most recent version online at http://mit.edu/fintel/www/modality.pdf

von Fintel, K.; Gillies, A. S. 2007. An opinionated guide to epistemic modality. Oxford Studies to Epistemology 2: 32-62.

Giannakidou, A. 1994. Subjunctive, habituality and negative polarity items. Semantics and Linguistic Theory (SALT) V, p.132-50.

- 2009. The dependency of subjunctive revisited: temporal semantics and polarity. Lingua 119(12): 1883-908.

Grice, H. P. 1975. Logic and Conversation. In: Cole, Peter (org.) Syntax and Semantics 9: Pragmatics, p.113-27. New York, Academic Press.

Guimarães, M. 2016. O advérbio realmente: modalidade epistêmica e implicaturas. Revista da Abralin 1: 75-99.

Ilari, R.1996. Sobre advérbios focalizadores. In: R. Ilari (org.) Gramática do português falado II: níveis de análise linguística. Campinas, editora da UNICAMP, p.192-212.

Kratzer, A. 2012. Modals and conditionals: new and revised perspectives. Oxford: Oxford Univeristy Press.

Lacerda, P. F. A. C. 2012. A multifuncionalidade do advérbio "realmente" na língua portuguesa sob a perspectiva da gramaticalização de construções. Alfa (São Paulo) 56(1): 169-200.

Marques, R.; Pires de Oliveira, R. 2016. Mood and Modality. In W. Leo Wetzels, S. de Moura Menuzzi and J. Costa (eds.) Handbook of Portuguese Linguistics. Wiley Blackwell, to appear, p.408-24.

Martins, H.; El-Jaick, A. P. 2012. Tem certeza? In: Lia Levy; Luiz Carlos Pereira; Marco Zingano (orgs.) Metafísica, lógica e outras coisas mais. Rio de Janeiro: NAU, v. 1, p.99-114.

Mortari, C. A. e Pires de Oliveira, R. 2014. Operadores modais: sistemas formais e línguas naturais. ReVEL (edição especial) 8: . [www.revel.inf.br]

Paradis, C. 2015. Between epistemic modality and degree: the case of really. Disponível em http://lup.lub.lu.se/luur/download?func=downloadFile\&recordOId=527128\&fileOId= 1590141, consultado em 17 de abril de 2015.

Principia 20(1): 127-142 (2016). 
Portner, P. 2009. Modality. Oxford: Oxford University Press.

PROJETO NURC. 2015. Projeto norma linguística urbana culta do Rio de Janeiro. Disponível em www.letras.ufrj.br/nurc-rj. Acesso em 18 de abril de 2015.

Stalnaker, R. 1968. A theory of conditionals. In: N. Rescher (ed.) American philosophical quarterly monograph v. ii: studies in logical theory. Oxford, Basil Blackwell, p.98-112.

Roberta Pires DE Oliveira Universidade Federal de Santa Catarina Universidade Federal do Paraná

$\mathrm{CNPq}$ ropiolive@gmail.com

MÁrcio RENATO Guimarães Departamento de Linguística, Letras Clássicas e Vernáculas Universidade Federal do Paraná magnusmartius@gmail.com

\section{Notes}

${ }^{1}$ A obra monumental de Kratzer inicia na década de 80. Kratzer (2012) é uma compilação revisada desses artigos, acrescida com os diferentes avanços da literatura sobre o tema.

2 Para uma apresentação formalizada passo a passo da Semântica de Ordenação de Kratzer veja Mortari \& Pires de Oliveira (2014).

${ }^{3} \mathrm{Na}$ fala informal é comum ouvirmos na real que talvez seja uma redução de na realidade. Vamos tratar esses sintagmas preposicionados como sinônimos do advérbio realmente.

${ }^{4}$ Essa interpretação é também possível com (1) em especial se o advérbio for prosodicamente acentuado. Há marcações entoacionais importantes que iremos negligenciar porque nosso foco é a semântica.

${ }^{5}$ O NURC - Norma Urbana Culta - é um projeto que envolve a gravação e análise de conversas informais. Veja o site www.letras.ufrj.br/nurc-rj.

${ }^{6}$ Uma small clause, em termos sintáticos.

${ }^{7}$ Dado retirado da internet.

${ }^{8}$ Um trabalho experimental de verificação dessa afirmação seria muito bem vindo!

${ }^{9}$ Essa afirmação aparece em vários autores, em particular de vertente funcionalista.

${ }^{10}$ Para uma descrição do modo no português ver Marques \& Pires de Oliveira 2016.

Principia 20(1): 127-142 (2016). 